\title{
Infectious Disease Acquisition in Pediatric International Travelers: A 10-Year Review at a Canadian Tertiary Care Hospital
}

\author{
Stavros Lalos ${ }^{1}$, Daniel S. Farrar ${ }^{2}$, Michelle Science ${ }^{3,4}$, Shaun K. Morris ${ }^{2,3,4,5^{*}}$ \\ ${ }^{1}$ The Royal College of Surgeons (RCSI), Dublin, Ireland \\ ${ }^{2}$ Centre for Global Child Health, The Hospital for Sick Children, Toronto, Canada \\ ${ }^{3}$ Division of Infectious Diseases, The Hospital for Sick Children, Toronto, Canada \\ ${ }^{4}$ Department of Pediatrics, University of Toronto, Toronto, Canada \\ ${ }^{5}$ Dalla Lana School of Public Health, University of Toronto, Toronto, Canada
}

Corresponding Author: Shaun Morris, MD, MPH, FRCPS(C), FAAP, DTM\&H, Associate Professor, Division of Infectious Diseases, The Hospital for Sick Children, 555 University Avenue, Toronto, ON M5G 1X8, Canada, Tel: +1-416 813-7654, Email: shaun. morris@sickkids.ca

Received June 18, 2020; Accepted October 6, 2020; Online Published November 23, 2020

\begin{abstract}
Introduction: Children are frequent international travelers and may acquire serious infectious diseases during travel. We undertook a retrospective 10-year review examining children admitted to hospital with infectious diseases associated with international travel at a Canadian tertiary care pediatric hospital.

Methods: Retrospective chart review was performed on select travel-related infectious diseases in children ranging in age from birth to $<18$ years who were admitted at the Hospital for Sick Children in Toronto between January 1st, 2009 and December 31st, 2018. Cases were identified using ICD-10 discharge codes. Patient demographics, travel history, epidemiological data, disease, and prophylaxis history were documented.

Results: A total of 154 children were hospitalized with a travel-related infection over a 10 -year period. The most common diagnoses were typhoid or paratyphoid fever $(n=58,38 \%)$, malaria $(n=57,37 \%)$, and hepatitis $A(n=14,8 \%)$. The median age of those infected was 8 years (IQR 3-12). There were 120 (78\%) children who were Canadian born, 31 (20\%) immigrants and $3(2 \%)$ who were visiting Canada. Of those who lived in Canada, $112(90 \%)$ travelled for the purpose of visiting friends and relatives (VFR), $6(5 \%)$ for tourism and $2(2 \%)$ for humanitarian work. India was typically known for the acquisition of infection for typhoid or paratyphoid fever, and Nigeria for malaria. Hepatitis A was most commonly acquired in Pakistan.

Conclusion: Imported infectious diseases continue to be a significant issue in travelers returning from trips suggesting improved preventative pre-travel care. VFR children are a group that should, in particular, be targeted for appropriate pre-travel advice and care.

Keywords: Child, Travel, Communicable Diseases, Travel-Related Illness, Canada
\end{abstract}

Citation: Lalos S, Farrar DS, Science M, Morris SK. Infectious disease acquisition in pediatric international travelers: a 10-year review at a Canadian tertiary care hospital. Int J Travel Med Glob Health. 2021;9(1):25-30. doi:10.34172/ijtmgh.2021.05.

\section{Introduction}

International travel is associated with an elevated risk of infectious disease acquisition, attributable to exposure to contaminated foods and water systems, insect and arthropod vectors, and atypical activities and behaviors. ${ }^{1-3}$ The number of annual international travelers is increasing and in 2019, the number of international tourist arrivals surpassed 1.5 billion, a $4 \%$ rise compared to the previous year. ${ }^{4}$ In Canada, children constitute $7 \%$ of international travelers to destinations other than the United States. ${ }^{5}$ Although this is a relatively small number of total travelers, pediatric travelers notably have different risk factors for acquiring infections, and disproportionately experience more severe illnesses than adults. ${ }^{6}$

Compared to adults, children are more likely to travel for the purpose of visiting friends and relatives (VFR), and thus belong to an important group known to be at higher risk for travel-acquired infections and other morbidities. ${ }^{7}$ VFR travelers are at higher risk for travel-acquired infectious because they tend to travel for longer periods of time and to more rural or remote areas. They are also less likely to seek pre-travel health consultation and obtain chemoprophylaxis

Copyright (C) 2021 The Author(s). This is an open-access article distributed under the terms of the Creative Commons Attribution License (http:// creativecommons.org/licenses/by/4.0), which permits unrestricted use, distribution, and reproduction in any medium, provided the original work is properly cited. 
and travel vaccines, and are more likely to be exposed to unsafe food or water sources. ${ }^{7-9}$ Compared to adults, children are less likely to obtain pre-travel advice and be offered post-travel medical care, hence more likely to require hospitalization ${ }^{10}$. The most common illnesses acquired by child travelers are diarrheal, respiratory, and dermatologic disease, as well as systemic febrile illness., ${ }^{71,12}$

According to the most recent Canadian census, there were over 7.5 million foreign-born individuals living in the country, more than one-fifth $(21.9 \%)$ of Canada's total population. ${ }^{13}$ In Canada, the majority of immigrants and visible minority groups live in urban centers, including more than 2.7 million in the Toronto Census Metropolitan Area. ${ }^{14}$ These individuals encompass approximately 70\% of Ontario's and 36\% of Canada's overall immigrant populations. ${ }^{14}$ Additionally, the visible minority population was generally younger than the overall population. ${ }^{15}$

The Hospital for Sick Children (SickKids) in Toronto is the main tertiary care pediatric health centre in the Greater Toronto Area. We aim to describe the frequency and distribution of key travel-acquired infectious diseases as well as the patient-level characteristics and demographics, travel patterns, and clinical outcomes in children seen as inpatients over a ten-year period at SickKids.

\section{Methods}

This study is a retrospective case series of select travelrelated infectious diseases in children aged 0-17 years who were admitted to SickKids between January $1^{\text {st }}, 2009$ and December $31^{\text {st }}, 2018$. Cases were identified using International Classification of Disease-10 (ICD-10) diagnostic codes that are assigned to every patient's chart at discharge by medical record professionals. The list of ICD-10 codes included in this study was developed by the consensus of the senior authors (SM and MS) and includes important infections that are always or most often acquired by travelers.

All charts of patients that were admitted between the dates of study that had at least one of the pre-specified ICD-10 codes were reviewed and assessed for inclusion. Cases were excluded if they were $\geq 18$ years old, if the patient was seen only as an out-patient, if the infection was not the primary reason for admission, or if the review of the chart determining the infection was not acquired in a foreign country.

During chart review, we extracted data pertaining to demographic characteristics, travel history, clinical course during illness, epidemiologic exposure history, past medical conditions, diagnostic methods, and antibiotic resistance. Demographic information included the status of each patient in Canada including if they were (1) born in Canada, (2) immigrants to Canada, or (3) traveling to Canada. If available, relevant travel history included any travel in the twelve months prior to the date of admission, the associated departure and return dates, and countries visited. Layovers that were less than 24 hours were excluded as official destinations. Region of travel was classified with regards to the WHO classification of countries with the following exceptions: Myanmar, Laos, Cambodia, Vietnam, Indonesia, Philippines, Thailand, Papua New Guinea, East Timor, Brunei, Malaysia, and Singapore, were categorized as 'Southeast Asia.' ${ }^{16}$

A person whose travel originated in Canada and whose purpose of travel was to visit friends or relatives was recorded as "VFR". An immigrant was defined as an individual who was born outside Canada and who lives in Canada now, with Canada being their country of current residence. We also recorded instances where patients received hospital care during travel (i.e. before admission to SickKids). In terms of diagnoses, patients who acquired their infection during travel were recorded as a "travel-related infection". Patients who immigrated to Canada and upon their arrival in Canada presented with an infection acquired in the country of origin were recorded as "imported infection acquired in home country prior to arrival". Diagnoses were categorized as either a travel-related infection or an imported infection acquired in the country of origin, according to the relation of diagnosis to travel defined by the GeoSentinel network. ${ }^{17}$ Microbiologically confirmed cases were labeled as confirmed. Cases labeled as suspected were instances where the attending medical team clinically diagnosed the infection and managed it as such, but microbiologic confirmation was not obtained.

Differences between VFR and non-VFR travelers were assessed using Mann-Whitney $U$ tests, $\chi^{2}$ tests, and Fisher exact tests, where appropriate. Negative binomial regression was employed to assess the change in the absolute number of travel-related infections over the study period as depicted in Figure 1. The data for this study was compiled using REDCap, and data analysis was conducted using Stata version 16.0 and Microsoft Excel. $P$ values of less than 0.05 were considered statistically significant.

\section{Results}

We identified 571 patients with primary discharge diagnoses matching our pre-specified list of ICD-10 codes between January 1, 2009 and December 31, 2018. These patients comprised 745 total visits, including 521 (70\%) in emergency, $222(30 \%)$ as hospitalized inpatients, and $2(<1 \%)$ for day surgery. Of the 222 hospitalized inpatients eligible for this study, $154(70 \%)$ charts were included in this study and 66 (30\%) were excluded. Reasons for exclusion included infections not related to travel $(n=35)$, infections acquired outside of the study inclusion dates $(n=8)$, and patient's not having the ICD-10 identified infection upon detailed review of the chart $(n=23)$.

The median age for children included was 8 years (IQR $3-12$ ), with $61 \%$ male and 39\% female. In total, 120 (78\%) children were Canadian-born, 31 (20\%) were immigrants, and 3 (2\%) were visiting Canada (Table 1). Of the 124 (79\%) children that were documented to have had travel originating in Canada (Canadian-born or previous immigrants), 112 (90\%) traveled for the purposes of VFR, 6 (5\%) were traveling for tourism and $2(2 \%)$ were traveling for humanitarian or missionary work. The remaining 4 (3\%) were traveling for reasons not specified or not ascertainable in the review.

As displayed in Table 2, of the included cases, 58 (38\%) were cases of typhoid or paratyphoid fever. The most common region to contract typhoid or paratyphoid fever was South Asia, including 25 (43\%) in India, 21 (36\%) in Pakistan, 


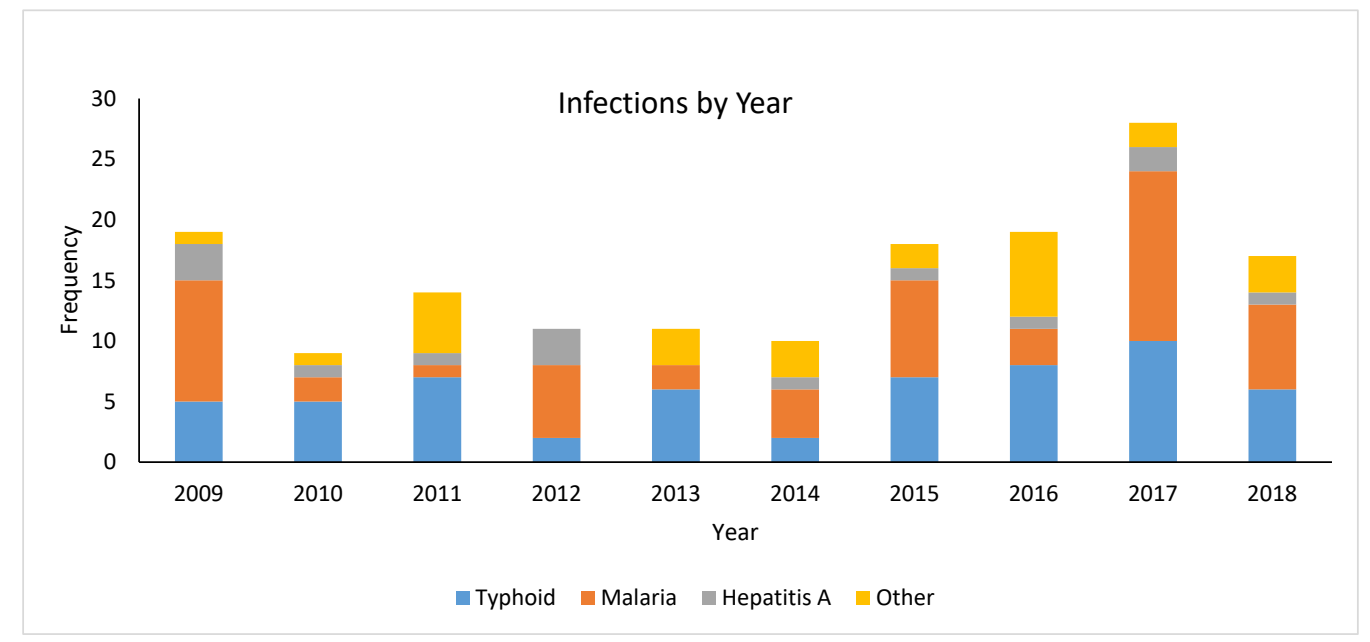

Figure 1. Number of Travel-Related Infectious Diseases at the Hospital for Sick Children Between 2009-2018. *No significant trend for increase in absolute number of admitted cases per year, $P=0.06$ by Negative Binomial Regression.

and $6(10 \%)$ in Bangladesh (Table 3). There were 57 (37\%) children admitted with malaria. Malaria was most commonly contracted in Africa, including 19 (33\%) in Nigeria, 7 (12\%) in Ghana, and $4(7 \%)$ in the Democratic Republic of the Congo. Of all malaria cases, 38 (67\%) were attributable to Plasmodium falciparum, 9 (16\%) to Plasmodium vivax, 6(11\%)

Table 1. Demographic, Travel History, And Admission Characteristics of The Study Sample

\begin{tabular}{|c|c|}
\hline Characteristics & \\
\hline Age, median (IQR) & $8(3-12)$ \\
\hline$\leq 1, \mathrm{n}(\%)$ & $3(2)$ \\
\hline $1-5, \mathrm{n}(\%)$ & $46(29)$ \\
\hline $5-15, \mathrm{n}(\%)$ & $89(57)$ \\
\hline $15-17, \mathrm{n}(\%)$ & $18(12)$ \\
\hline \multicolumn{2}{|l|}{ Sex, n (\%) } \\
\hline Female & $60(39)$ \\
\hline Male & $94(61)$ \\
\hline Status in Canada known, $\mathrm{n}(\%)$ & $156(100)$ \\
\hline Canadian born, n (\%) & $120(78)$ \\
\hline Immigrant, $\mathrm{n}(\%)$ & $31(20)$ \\
\hline Visiting Canada, n (\%) & $3(2)$ \\
\hline \multicolumn{2}{|l|}{ Reason for Travel $^{\mathrm{a}}$} \\
\hline Reason for travel from Canada, $\mathrm{n}(\%)$ & $124(79)$ \\
\hline Visiting friends or relatives (VFR), $\mathrm{n}(\%)$ & $112(90)$ \\
\hline Tourism, n (\%) & $6(5)$ \\
\hline Missionary/humanitarian, n (\%) & $2(2)$ \\
\hline Other/not specified, n (\%) & $4(3)$ \\
\hline \multicolumn{2}{|l|}{ Travel advice } \\
\hline Travel advice history documented, n (\%) & $122(79)$ \\
\hline Appropriate travel advice sought, $\mathrm{n}(\%)$ & $14(11)$ \\
\hline Inappropriate or no travel advice sought, n (\%) & $108(89)$ \\
\hline \multicolumn{2}{|l|}{ Admission type, n (\%) } \\
\hline Ward & $142(92)$ \\
\hline $\mathrm{ICU}$ & $12(8)$ \\
\hline Total & 154 \\
\hline
\end{tabular}

to Plasmodium ovale, and $4(6 \%)$ to unknown species. One adolescent had dual infection with $P$. falciparum and $P$. ovale ${ }^{18}$ in a travel to Ghana. Acute hepatitis A, which is not part of the routine immunization schedule in Ontario, was the third most common infection acquired abroad $(\mathrm{n}=14,9 \%)$ and was most commonly acquired in South Asia (8 in Pakistan [57\% of all hepatitis cases] and 2 in India [14\%]). There were 7 (4\%) cases of cysticercosis, 4 (2\%) cases of dengue fever, 2 (1\%) cases of ascariasis, and $2(1 \%)$ leishmaniasis and strongyloides infections each. Additionally, there was one child admitted with each of echinococcosis, yellow fever, brucellosis, leprosy, unspecified viral haemorrhagic fever, cholera, and schistosomiasis. Twelve patients $(8 \%)$ were admitted to ICU for higher level care, of whom 6 (46\%) were admitted for malaria, 4 (31\%) for typhoid or paratyphoid fever, and 1 (8\%) each for dengue, ascariasis and neurocysticercosis.

Of the 12 patients admitted to the ICU, 5 (42\%) were VFR travelers, compared to $7(58 \%)$ non-VFR's. There were 4

Table 2. Number of Cases of Imported Infectious Diseases

\begin{tabular}{lc}
\hline Infectious Disease ICD10 Code & No. (\%) \\
\hline Typhoid or paratyphoid fever & $58(38)$ \\
\hline Malaria & $57(37)$ \\
\hline Plasmodium falciparum malaria & $38(24)$ \\
\hline Plasmodium vivax malaria & $9(5)$ \\
\hline Other parasitologically confirmed malaria ${ }^{a}$ & $6(3)$ \\
$\quad$ Unspecified malaria & $4(2)$ \\
\hline Acute hepatitis A & $14(9)$ \\
\hline Cysticercosis & $7(5)$ \\
\hline Ascariasis & $2(1)$ \\
\hline Dengue & $4(3)$ \\
\hline Leishmaniasis & $2(1)$ \\
Strongyloidiasis & $2(1)$ \\
\hline Other & $8(5)$ \\
\hline Total & $\mathbf{1 5 4}$ \\
\hline a Plasmodium ovale malaria. & \\
\hline b Cholera, echinococcus, yellow fever, leprosy, viral hemorrhagic fever, other \\
zoonotic disease.
\end{tabular}


Table 3. Typhoid, Malaria and Hepatitis Exposure by Country and Region

\begin{tabular}{|c|c|c|c|}
\hline Region, n (\%) & $\begin{array}{c}\text { Typhoid and } \\
\text { Paratyphoid Fever }\end{array}$ & $\begin{array}{c}\text { Malaria (All } \\
\text { Species) }\end{array}$ & $\begin{array}{c}\text { Acute } \\
\text { Hepatitis A }\end{array}$ \\
\hline & $N=58$ & $N=57$ & $N=14$ \\
\hline \multicolumn{4}{|l|}{ Africa } \\
\hline Nigeria & $1(2)$ & $19(33)$ & - \\
\hline Ghana & - & $7(12)$ & - \\
\hline DR Congo & & $4(7)$ & - \\
\hline Guinea & - & $3(5)$ & - \\
\hline Uganda & - & $3(5)$ & - \\
\hline Cameroon & - & $2(3)$ & - \\
\hline Kenya & - & $2(3)$ & - \\
\hline Tanzania & - & $2(3)$ & - \\
\hline Other & $1(2)^{\mathrm{a}}$ & $4(7)^{b}$ & $1(7)^{c}$ \\
\hline Americas & $1(2)^{d}$ & $1(2)^{\mathrm{e}}$ & - \\
\hline \multicolumn{4}{|c|}{ Eastern Mediterranean } \\
\hline Afghanistan & - & $1(2)$ & $3(21)$ \\
\hline Other & $1(2)^{f}$ & - & - \\
\hline Southeast Asia & $1(2)^{g}$ & - & - \\
\hline \multicolumn{4}{|l|}{ South Asia } \\
\hline India & $25(43)$ & $2(3)$ & $2(14)$ \\
\hline Pakistan & $21(36)$ & $7(12)$ & $8(57)$ \\
\hline Bangladesh & $6(10)$ & - & - \\
\hline Other & $1(2)^{\mathrm{h}}$ & - & - \\
\hline
\end{tabular}

a 1 case acquired in Senegal.

b 1 case acquired in each of Angola, Benin, Central African Republic, and Cote

d'Ivoire.

c 1 case acquired in Sudan.

d 1 case acquired in St. Lucia.

e 1 case acquired in Dominican Republic.

${ }^{\mathrm{f}} 1$ case acquired in Iran.

g 1 case acquired in Philippines

h 1 case acquired in Sri Lanka.

(2.6\%) patients who were hospitalized for their illness while abroad for malaria $(n=1)$, typhoid $(n=2)$ and dengue $(n=1)$. A total of 122 patients (79\%) had a documented history of whether or not they had a pre-travel consultation of whom $108(89 \%)$ did not receive any pre-travel advice. Of the 14 (11\%) of patients who had any pre-travel advice, 7 (50\%) received their pre-travel advice from a general practitioner or their primary care provider and $5(36 \%)$ received pre-travel advice from a travel medicine specialist. Two (14\%) patients reported seeking advice only from a friend or a relative. Of the 112 VFR travelers, 9\% $(n=11)$ received appropriate pre-travel advice from a health professional compared to $17 \%(n=1)$ of non-VFR travelers $(P=0.04)$.

The median travel duration for VFR travelers was 36 days (IQR 27-81 days), compared to 24 days (IQR 7-68 days) for non-VFR travelers $(P=0.1)$. The median age of VFR travelers was 8 years (IQR 3-12 years), two years less than non-VFR travelers (median age 10 years, IQR $7-14$ years, $P=0.003$ ). One hundred and ten (98\%) VFR travelers reportedly stayed and ate at local homes, while 7 (58\%) of non-VFR travelers reported this.

Forty-six (30\%) patients were discharged from the ward with no further contact and $108(70 \%)$ were referred to the outpatient infectious diseases clinic for follow-up's. All 154 (100\%) included patients were alive at the time of discharge from hospital or follow-up clinic. Of all 154 patients, 103 $(66 \%)$ had complete resolution of infection at the final point of contact with the hospital or clinic. Forty-seven (31\%) had continuing treatment with a planned end date and $4(3 \%)$ had ongoing treatment with no planned end date. Between 2009 and 2018, there was a slight non-significant increase in the absolute number of admitted patients per year with travelrelated infections $(P=0.06$, Figure 1$)$.

\section{Discussion}

This study is consistent with earlier research that VFR children help the development of the greatest number of serious imported infections. ${ }^{19-22}$ In total, 112 (90\%) pediatric travelers were included in our study who traveled for the purpose of VFR. Pediatric VFR travelers are less likely to seek pre-travel health consultation, take anti-malarial chemoprophylaxis or take bite-prevention measures. ${ }^{19,23}$ This study includes a non-representative sample of all travelers (i.e. it includes only those who acquired a serious infection), but it is still notable that the number of patients who sought pre-travel advice was extremely low (11\%) and sub-optimal for both VFR and non-VFR travelers. The low rate of pretravel medical advice is particularly an issue for VFR travelers who were on average younger, had longer trip durations, and disproportionately stayed and consumed food in local homes. Barriers to obtaining pre-travel preventative care are well described for VFR travelers, and ongoing efforts are needed to mitigate risk in this population of children. ${ }^{24}$ These barriers are multifactorial and extend far beyond the perception of

Table 4. Travel Characteristics and Level of Care VFR/Non-VFR

\begin{tabular}{|c|c|c|c|}
\hline & VFR & Non-VFR & P Value* \\
\hline Length of travel (days), median (IQR) & 36 (IQR 27-81) & 24 (IQR 7-68) & 0.1 \\
\hline Age, median (IQR) & 8 (IQR 3-12) & $10($ IQR 7-14) & 0.0 \\
\hline Staying/eating local, n (\%) & $110(98)$ & $7(58)$ & 0.0 \\
\hline Animal exposure, $\mathrm{n}(\%)$ & $10(9)$ & $4(33)$ & 0.6 \\
\hline Unplanned medical/dental care, n (\%) & $2(2)$ & 0 & 0.5 \\
\hline Antibiotics taken during travel, $\mathrm{n}(\%)$ & $2(2)$ & 0 & 0.5 \\
\hline Intensive care unit (ICU) & $5(4)$ & $7(18)$ & \\
\hline General ward & $107(96)$ & $35(83)$ & \\
\hline
\end{tabular}

* Mann-Whitney $U$ tests, $\chi 2$ tests, and Fisher's exact tests, where appropriate. 
disease risk. ${ }^{10,24}$

While child VFR travelers may be at higher risk, it is important to emphasize the importance of pre-travel advice and appropriate preventative care in all travelers. In particular, it is optimal that pre-travel advice be sought from a trained health care professional rather than from informal sources such as a relative, the internet, or an embassy. In Ontario, where travel medicine is not publicly funded, primary care providers play an important role in counselling patients before traveling abroad. It is imperative that clinicians and health care workers offering travel advice be aware of the global epidemiology of disease and current travel trends. Clinicians should also be aware of the higher risk groups in their practice for the prevention of certain specific infections, in particular travelers to South Asia and West Africa who have higher risks of typhoid and malaria respectively. Interestingly, we identified one case of congenital Plasmodium vivax malaria in this study. Although very rarely seen in non-endemic countries, malaria should be under constant focus by clinicians since it may be congenitally transmitted.

There are several limitations to this study. We only collected data from a single tertiary care pediatric referral center in Toronto, and thus it is not representative of the entire Greater Toronto Area including cities surrounding Toronto that have an even greater proportion of foreign-born people. Similarly, our results may not be generalizable to cities in other parts of Canada or the world. We included only patients with a travel-acquired infection and do not have denominator data on the number of travelers, hence being unable to calculate rates. Our analysis of trend in number of travel-acquired infectious disease cases per year over the study time frame does not take into account differences in the total number of annual hospital admissions. Also, details of management and treatment course were not recorded. While we are able to categorize patients as VFRs or other types of traveler, we are not able to comment on the details of individual travelers, such as the foods consumed and type of accommodation. Finally, we only reviewed admitted inpatients and thus cannot comment on the majority of cases that were less severe and did not require admission to hospital.

\section{Conclusion}

This study establishes that children continue to be admitted to hospital with serious infectious diseases acquired during travel that could have been prevented. Pediatric patients traveling abroad are a distinctive risk group, and child VFR travelers are a particularly important sub-group. Trends in global travel and in demographics of large international cities such as Toronto suggest that the number of children at risk will probably increase in the future. While it is ideal for children to visit travel medicine practitioners, clinicians who look after children prior to travel should consider the demographics for their practice, including at-risk individuals and their conditions, to properly educate and safeguard children and families during international travels.

\section{Authors' Contributions}

SM and MS: Conceptualization, Writing, Review \& Editing,

\section{Research Highlights}

\section{What Is Already Known?}

International travel can expose travelers to a number of health risks, which vary depending on travel destination and individual factors. Prior research has shown that VFR travelers (visiting friends and relatives) are at a higher risk of acquiring travel related infections. Children are more likely to travel for the purpose of visiting friends and relatives (VFR). VFR travelers present an increased risk of acquiring an infection abroad because they travel for longer periods of time and to more rural or remote areas. Children are also less likely to have obtained formal pretravel advice, seek post-travel health care, and are more likely to require hospitalization.

\section{What This Study Adds?}

Our study identified that imported infectious diseases continue to be a significant issue in child travelers. We also recognized gaps in pre-travel preventative care. Over a 10-year period at a major tertiary pediatric hospital the most common diagnoses of imported infections were typhoid or paratyphoid fever $(n=58,38 \%)$, malaria $(n=57$, $37 \%)$, and hepatitis $A(n=14,8 \%)$. Most of these infections are preventable with appropriate pre-travel advice and prophylaxis. We believe that this work will be of significant interest to pediatric health care practitioners who provide pre-travel advice and post-travel care.

Supervision. SL: Data curation, Writing, Original draft preparation, Visualization, Formal analysis. DF: Formal analysis, Data curation, Software.

\section{Conflict of interest Disclosures}

No conflicts of interest to declare.

\section{Ethical Approval}

This study was approved by the SickKids Research Ethic Board (REB \# 1000062957).

\section{Funding/Support}

This research did not receive any specific grant from funding agencies in the public, commercial, or not-for-profit sectors.

\section{Acknowledgments}

We would like to thank all of the administrative staff at SickKids who assisted with the organization of this project, including Nadine Francis and Jenna Craig who offered their assistance and support. We would also like to thank the clerical staff in medical records.

\section{References}

1. Audcent T, Hunter A. Fever in the returning child traveller: highlights for health care providers. Paediatr Child Health. 2018;23(8):553554. doi:10.1093/pch/pxy138.

2. Angelo KM, Kozarsky PE, Ryan ET, Chen LH, Sotir MJ. What proportion of international travellers acquire a travel-related illness? A review of the literature. J Travel Med. 2017;24(5). 
doi:10.1093/jtm/tax046.

3. Chen LH, Blair BM. Infectious risks of traveling abroad. Microbiol Spectr. 2015;3(4). doi:10.1128/microbiolspec.IOL5-0005-2015.

4. World Tourism Organization (UNWTO). International Tourist Arrivals Reach 1.4 Billion Two Years Ahead of Forecasts. UNWTO; 2019. http://www2.unwto.org/press-release/2019-01-21/ international-tourist-arrivals-reach-14-billion-two-years-aheadforecasts.

5. Statistics Canada. Canada at a Glance, 2007. Ottawa: Minister of Industry; 2008. p. 1704-8249.

6. Ghoshal M, Kanjilal S. Travel-related infection in children: pretravel counseling to reduce morbidity. US Pharm. 2017;42(4):HS21HS28. https://www.uspharmacist.com/article/travelrelatedinfection-in-children-pretravel-counseling-to-reduce-morbidity.

7. Hagmann S, Benavides V, Neugebauer R, Purswani M. Travel health care for immigrant children visiting friends and relatives abroad: retrospective analysis of a hospital-based travel health service in a US urban underserved area. J Travel Med. 2009;16(6):407-412. doi:10.1111/j.1708-8305.2009.00357.x.

8. Leder $\mathrm{K}$, Tong $\mathrm{S}$, Weld $\mathrm{L}$, et al. Illness in travelers visiting friends and relatives: a review of the GeoSentinel Surveillance Network. Clin Infect Dis. 2006;43(9):1185-1193. doi:10.1086/507893.

9. Ma XW, Pell LG, Akseer N, et al. Characteristics and pre-travel preparation of travelers at a Canadian pediatric tertiary care travel clinic: a retrospective analysis. Travel Med Infect Dis. 2016; 14(2):148-154. doi:10.1016/j.tmaid.2015.11.012.

10. Hagmann S, Neugebauer R, Schwartz E, et al. Illness in children after international travel: analysis from the GeoSentinel Surveillance Network. Pediatrics. 2010;125(5):e1072-1080. doi:10.1542/peds.2009-1951.

11. Hunziker T, Berger C, Staubli G, et al. Profile of travel-associated illness in children, Zürich, Switzerland. J Travel Med. 2012; 19(3):158-162. doi:10.1111/j.1708-8305.2012.00611.x.

12. Newman-Klee C, D'Acremont V, Newman CJ, Gehri M, Genton B. Incidence and types of illness when traveling to the tropics: a prospective controlled study of children and their parents. Am J Trop Med Hyg. 2007;77(4):764-769.

13. Government of Canada Statistics Canada. The Daily — Immigration and Ethnocultural Diversity: Key Results from the 2016 Census.
Ottawa: Statistics Canada; 2017.

14. Government of Ontario MoF. 2016 CENSUS HIGHLIGHTS: Factsheet 8. Ontario: Ministry of Finance; 2016. https://www.fin. gov.on.ca/en/economy/demographics/census/cenhi16-8.html.

15. Chui TW, Statistics Canada. Immigration and Ethnocultural Diversity in Canada: National Household Survey, 2011. Ottawa: Statistics Canada; 2011.

16. World Health Organization (WHO). List of Member States by WHO Region and Mortality Stratum. https://www.who.int/choice/ demography/mortality_strata/en/.

17. Leder K, Torresi J, Libman MD, et al. GeoSentinel surveillance of illness in returned travelers, 2007-2011. Ann Intern Med. 2013; 158(6):456-468. doi:10.7326/0003-4819-158-6-20130319000005.

18. Senn H, Alattas N, Boggild AK, Morris SK. Mixed-species Plasmodium falciparum and Plasmodium ovale malaria in a paediatric returned traveller. Malar J. 2014;13:78. doi:10.1186/1475-2875-13-78.

19. Ladhani S, Aibara RJ, Riordan FA, Shingadia D. Imported malaria in children: a review of clinical studies. Lancet Infect Dis. 2007;7(5):349-357. doi:10.1016/s1473-3099(07)70110-x.

20. Hotez PJ, Odom John AR, LaBeaud AD. Pediatric tropical medicine: the neglected diseases of children. PLoS Negl Trop Dis. 2019;13(5):e0007008. doi:10.1371/journal.pntd.0007008.

21. Zhou K, Sauve LJ, Richardson SE, Ford-Jones EL, Morris SK. Enteric fever in a multicultural Canadian tertiary care pediatric setting: a 28-year review. J Pediatric Infect Dis Soc. 2017;6(1):98-101. doi:10.1093/jpids/piw007.

22. Evans AB, Kulik D, Banerji A, et al. Imported pediatric malaria at the Hospital for Sick Children, Toronto, Canada: a 16 year review. BMC Pediatr. 2014;14:251. doi:10.1186/1471-2431-14-251.

23. Fong EKK, Pell LG, Faress A, et al. Adherence to recommendations at a Canadian tertiary care Family Travel Clinic-A single centre analysis. Travel Med Infect Dis. 2020;34:101579. doi:10.1016/j. tmaid.2020.101579.

24. Walz EJ, Volkman HR, Adedimeji AA, et al. Barriers to malaria prevention in US-based travellers visiting friends and relatives abroad: a qualitative study of West African immigrant travellerst. J Travel Med. 2019;26(2). doi:10.1093/jtm/tay163 